\title{
Benign Goitre of the Child: Experience of Paediatric Surgery Service A - Rabat about 15 cases
}

\author{
Khlifi Asmaa*, Oulahyane R, Abdelhak M, Benhmamouch MN and Kisra M \\ Paediatric Surgery Service A, Children's Hospital, Rabat, Morocco
}

Received: May 10, 2019; Published: June 12, 2019

*Corresponding author: Khlifi Asmaa, Paediatric Surgery Service A, Children's Hospital, Rabat, Morocco

Keywords: Goitre; Enfant; Diagnostic; Treatment

\section{Introduction}

Goiter is the most common endocrine disease in the world: however, it is uncommon in children compared to adults with a higher risk of malignancy, hence the value of careful clinical examination and a rigorous follow-up in front of any goitre even initially benign [1]. Thyroid surgery in children is part of an overall multidisciplinary management [2]. The gesture itself has specificities in terms of technical realization and postoperative complications. The goal of surgical treatment is to achieve the highest therapeutic efficacy with the lowest morbidity [3].

\section{Methods and Results}

Our work consists of a retrospective study of 15 cases collected in the Pediatric Surgery A department of Rabat Children's Hospital over a period of 13 years, from March 2002 to September 2015. The aim of this work is to expose the different epidemiological, clinical, paraclinical and histopathological aspects of benign goitres operated during this period, as well as the indications, the efficacy and the undesirable effects of surgical treatment of the thyroid in children.

\section{Our Patients}

10 girls and 5 boys have an average age of 12 years, $80 \%$ consulted for isolated cervical swelling. After a complete clinical examination, the paraclinical explorations are represented by the ultrasound as well as the thyroid scintigraphy. Thoracic $\mathrm{X}$-ray of the thorax was also systematically requested in all our patients. Cervical CT was performed in only one patient (9\%). The hormonal assessment was done in all patients, it revealed a dysthyroidism in 2 patients. Puncture was convenient in 3 normal returning patients. Surgical treatment was retained in 14 patients $(93 \%)$. The actions performed are total thyroidectomy in 5 patients (33\%), lobo-isthmectomy in 8 patients $(53 \%)$. Operated thyroid conditions are dominated by thyroid adenomas
(8 cases), vesicular adenomas (6 cases), oncocytic adenoma ( 1 case) and papillary adenoma (1 case). The postoperative course was simple in 9 patients. There was one case of transient recurrent paresis (9\%), and one case of transient hypocalcemia in one patient $(9 \%)$.

\section{Discussion}

The thyroid disease in children is relatively rare compared to that of the adult, which explains the decreased annual number of cases operated in children, even at major surgery centers. These low numbers lead to the search for a large sample of population from which conclusions can be drawn regarding updating practices in the pathology of the thyroid in children. In a multicenter European study of 75,599 children aged 6-17, the prevalence of goiter is $>5 \%$, which could be explained by genetic or environmental factors in the different populations [4]. In our series, endemic goitre is present in $13 \%$ of cases whereas in the El Arabi series [5] it is of the order of (46\%), and the TANZ series [6] is of the order of $50 \%$.

The analysis of the age of patients in our series showed that the frequency increased with age; with a peak occurring around the age of 11-13 years. The average age of our patients is 12 years, it is lower than that found in other series; with extremes ranging from 9 to 16 years old. A clear female predominance characterizes the thyroid pathology with a sex ratio between 3 and 4 [7]. On the other hand, the literature agrees that the risk of malignancy of a nodule is higher in the male sex [8].

According to UNICEF, the prevalence of goiter in Morocco among children aged 6 months to 12 years reaches $77 \%$ in mountainous regions. In our series, there is a slight urban predominance, 5 patients $(33 \%)$ are from goitrous endemic areas. A retrospective study done at the University of Wisconsin 
and American Family Children's Hospital by Jocelyn F, Burke, Rebecca S, Sippel, and Herbet Chen between 1994 and 2009 78 thyroid operations in pediatrics showed an increase in the rate of thyroid pathology at the child and a clear increase in the indication of surgery in benign thyroid disease as well as the indication of total thyroidectomy compared to partial thyroidectomy [9].

Data from international studies and individual studies of the institutions have concluded that endocrine surgery should be performed by high-level pediatric surgeons who have practiced in large centers of endocrine surgery, this is the condition to reduce the rate of complications in post-operative and length of hospital stay $[10,11]$. One of the advantages of an interdisciplinary endocrine center is the faster adoption of technology; thus fine-needle aspiration has been recommended by the American Thyroid Association as the first diagnostic tool in adults [12], but it has been used less in children even if the risk of cancer is high. children with nodules is higher than in adults $[13,14]$. Concern for a higher risk of complications in children who have undergone thyroidectomy compared to adults has led to recommending partial thyroidectomy for all single nodules [15].

However the study from the University of Wisconsin and American Family Hospital Children, shows that the complications

Table 1: Total Thyroidectomy vs Partial Thyroidectomy.

\begin{tabular}{|c|c|c|c|}
\hline & Total Thyroidectomy & Thyroidectomy partial & Resection of the nodule \\
\hline Stephan Scholz et al. & $29 \%$ & $60 \%$ & $11 \%$ \\
\hline Jocelyn F. et al. & $70 \%$ & $30 \%$ & - \\
\hline Our study & $39 \%$ & $62 \%$ & $7 \%$ \\
\hline
\end{tabular}

Total thyroidectomy was performed in $29 \%$ of cases, isthmus lobectomy in $60 \%$ of cases and isolated nodule resection in $11 \%$. The incidence of thyroid nodules peaks in adolescence with a clear female predominance 3.7 / 1 [22] (Table 1). Our study is consistent with the study of Stephan Scholz et al. a partial thyroidectomy was performed for 8 patients: $62 \%$ of cases with a totalization for two patients. Total thyroidectomy was indicated in 5 patients: $39 \%$ of cases, 3 for prophylaxis and 2 are similar to the adult series with no notion of increased risk compared with the increase in the rate of total thyroidectomy, furthermore it has It has been shown that the recurrence rate with partial thyroidectomy is very high even with small tumors (20\% to $30 \%$ ) and most often requires surgical reintervention [16]. In agreement with recent studies [17], this study showed an increase over time in the percentage of total thyroidectomy compared to partial thyroidectomy from $58 \%$ to $85 \%$ with a significant increase in the number of patients undergoing total thyroidectomy for total thyroidectomy. a benign pathology.

Studies show a decrease in complication rates with no recurrence of the disease after a median of 9 years [18,19]. In total, with definitive surgical treatment for a benign pathology, patients are allowed to avoid the high rate of relapse and toxicity related to the use of antithyroid drugs such as propylthiouracil and methimazole, as well as the risks associated with use of radioactive iodine [20,21]. A retrospective study by Stephan Scholz et al. at the Boston Children's Hospital between 1970 and 2004 showed a total of 175 children who underwent surgery for thyroid pathology. Surgical excision is the recommended treatment for abnormal cytology of thyroid nodules and hyperthyroidism. Of the 175 children requiring thyroid surgery at Boston Children's Hospital, thyroid nodules were by far the most common indication (83\%). Followed by hyperthyroidism (7\%), goitre (7\%), NEM2 (2\%). for a GMHN. Partial thyroidectomy was performed for a benign pathology in 6 out of 8 patients. According to Jocelyn F. et al. the benign pathology is predominant, dominated by the disease of base, the goitres then the adenomas. This is consistent with the results of Stephan Scholz et al. However, it is the adenomas that are preponderant in this study. The results of our study are consistent with the results of the literature, with a predominance of benign pathology, adenomas present (30\%) (Figure 1).
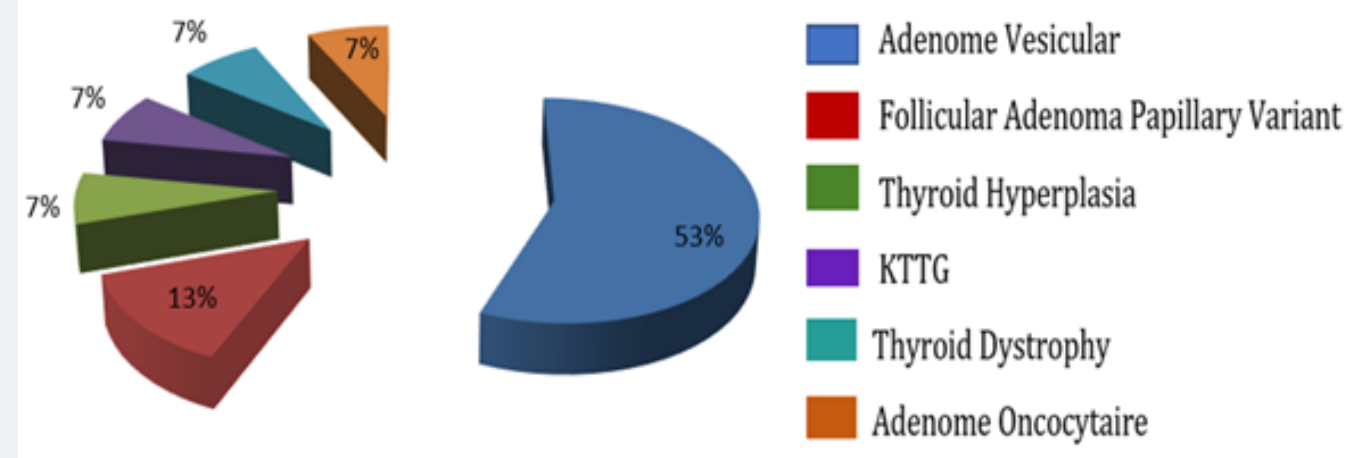

Figure 1: The anatomopathological results in our series. 


\section{Conclusion}

The surgical indication is usually the result of joint reflection by the endocrinologist and the surgeon. Thyroid surgery is a common surgery but not without complications, the most formidable of which are recurrence and permanent hyperparathyroidism. The experience of all surgical teams in the field of vascular anatomy of the neck is the best guarantee to reduce these complications and prevent them.

\section{References}

1. Lloyd RV, Douglas BR, Young WF (2002) Endocrine diseases. First Series ed. American registry of pathology and Armed forces institute of pathology.

2. Tuggle CT, Roman SA, Wang TS (2008) Pediatric endocrine surgery: who is operating on our children? Surgery 144(6): 869-877.

3. Kim YS (2012) Impact of preserving the parathyroid glands on hypocalcemia after total thyroidectomy with neck dissection. J Korean Surg Soc 83(2): 75-82.

4. Delange F (2000) Iodine deficiency. (The Thyroid: fundamental and clinical text) Lippincott, Philadelphia, US State, pp: 295-316.

5. HEl Arabi, MEl Fares, F Jennane, F Dehbi (2010) CL010 - Goitre thyroïdien de l'enfant : à propos de 31 cas. Archives de Pédiatrie 17(6): 3-4.

6. Tanz R, Benhammou B, Gaouzi A, Abentahila L, Chat Y, et al. Goitre de l'enfant: à propos de 123 cas.

7. Boudaya M, Germazi F, Drira MM (1999) Cancers de la thyroïde. In : Maalej M, Carcinologie Pratique. Collection M/Sciences médicales 199208.

8. Belfiore A, La Rosa GL, LA Porta GA (1992) Cancer risk in patient with cold thyroid nodes: relevance of iodine intake, sex, age and multinodularity. Am J Med 363-369.

9. Jocelyn F, Burke, Rebecca S, Sippel, Herbert Chen (2012) Evolution of pediatric thyroid surgery at tertiary medical centre. J Surg Res 177: 268-274.

10. Sosa JA, Tuggle CT, Wang TS (2008) Clinical and economic outcomes of thyroid and parathyroid surgery in children. J Clin Endocrinol Metab 93: 3058.
11. Wang TS, Roman SA, Sosa JA (2008) Predictors of outcomes following pediatric thyroid and parathyroid surgery. Curr Opinion Oncol 21: 23.

12. Mallick UK (2010) The revised American thyroid association management guidelines 2009 for patient with differentiated thyroid cancer: an evidence-based risk adapted approach. Clin Oncol R Coll Radiol 22: 472.

13. Altincik A, Demir K, Abaci A, Böber E, Büyükgebiz A (2010) Fine-needle aspiration biopsy in the diagnosis and follow-up of thyroid nodules in childhood. J Clin Res Ped Endo 2: 78.

14. Stevens C, Lee JKP, Sadatsafavi M, Blair GK (2009) Pediatric thyroid fine-needle aspiration cytology: a meta-analysis. J Ped Surg 44: 2184 2191.

15. Khozeimeh N, Gingalewski C (2011) Thyroid nodules in children: A single institution's experience. J Oncol.

16. Rivkees SA, Mazzaferri EL, Verburg FA (2011) The treatment of differentiated thyroid cancer in children: emphasis on surgical approach and radioactive iodine therapy. Endocr Rev 32: 798.

17. Ho Twt, Shaheen AA, Dixon E, Harvey A (2011) Utilization of thyroidectomy for benign disease in the United States: a 15- Year population-based study. Am J Surg 201: 570.

18. Raval MV, Browne M, Chin AC (2009) Total thyroidectomy for benign disease in the pediatric patient feasible and safe. J Ped Surg 44: 1529.

19. Efremidou EI, Papageorgiou MS, Liratzopoulos N, Manolas KJ (2009) The efficacy and safety of total thyroidectomy in the management of benign thyroid disease: a review of 932 cases. Can J Surg 52: 39.

20. Baker B, Shapiro B, Fig LM (1989) Unusual complications of antithyroid drug therapy: four case reports and review of literature. Thyroidology $1: 17$.

21. Livadas S, Xyrafis X, Economou F (2010) Liver failure due to antithyroid drugs: report of a case and literature review. Endocrine 38: 24.

22. Stephan Scholz, Jessica R Smith, Beverly Chaignaud, Robert C, Shamberger, et al. (2011) Thyroid surgery at children's hospital Boston: a 35- year single institution experience. J Pediatr Surg 46: 437-442.

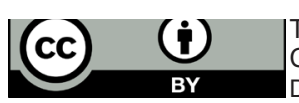

This work is licensed under Creative Commons Attribution 4.0 Licens DOI:_10.19080/OAJS.2019.10.555793 